\title{
Roboter post portas
}

\section{Liebe Leserinnen und Leser,}

im Controlling scheint es aktuell keine spannendere Frage zu geben als die, wie sich das Zusammenspiel zwischen Controllern und ihren elektronischen Hilfsmitteln entwickeln wird. Besonders trefflich lässt sich darüber spekulieren, wann die Künstliche Intelligenz die natürlichen Entscheidungen abnehmen wird und welche Folgen daraus für die Controller (und ihre Manager!) resultieren. Viele beschleicht hier eher ein ungutes Gefühl bis hin zur Angst, auf Sicht den Arbeitsplatz zu verlieren, andere kümmern sich noch gar nicht um das Thema, weil sie es für reine Zukunftsmusik halten. Und in der Tat liegt in Unternehmen zwischen einer Idee und ihrer Realisierung häufig ein erheblicher Timelag. Probleme beim Wissen, wie die Idee genau funktioniert, Skepsis, ob sie wirklich auf den eigenen Kontext passt, eine generelle Angst vor Veränderung und drängende Alltagsprobleme führen dazu, dass es häufig so lange dauert - und vermutlich wird es der Entscheidungsunterstützung à la „Alexa, was soll ich tun?" ebenso gehen.

Aber die Digitalisierung bezieht sich ja nicht nur auf diese Königsdisziplin, sondern auch auf ganz profane, eher gänzlich unspannende Themen wie die Automatisierung von Controlling-Prozessen. Und die stehen nicht mehr vor der Tür, sondern haben in der Form von Computer-Programmen die Türschwelle in vielen Unternehmen bereits seit geraumer Zeit überschritten. Das Prinzip von Bots ist schnell zu verstehen, ihr Funktionieren ist leicht anhand von Pilotanwendungen gezeigt, sie schaffen Kapazität für Alltagsprobleme, und Controller, die Angst vor ihrer Einführung haben, sind uns auch noch nicht begegnet!

Und es kommt noch ein wichtiger Punkt hinzu: Bots brauchen eine „saubere“ Prozessbasis! Digitalisierung insgesamt ist ohne sie nicht möglich und auch eine Einführung von SAP S/4 Hana nicht. Wenn die Prozesse nicht durchstrukturiert und standardisiert sind, macht ihre automatische Verbindung per Software keinen Sinn. Ineffizienzen werden damit nur zementiert statt behoben. Unternehmen erkennen zunehmend, wie wichtig eine aufgeräumte Prozesslandschaft ist, und investieren erhebliche Kapazität über einen langen Zeitraum. Dabei sind häufig die Unternehmen vorne in der Entwick-

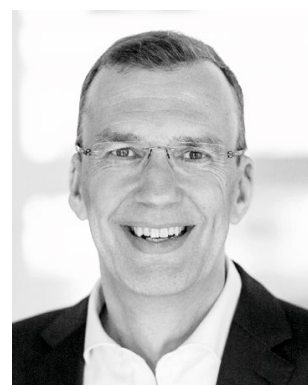

Utz Schäffer

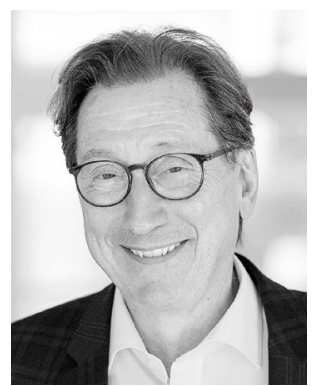

Jürgen Weber lung, die schon frühzeitig Shared Service Centers aufgebaut haben, da für diese eine saubere Prozessdefinition und Standardisierung ebenfalls unverzichtbar ist. Hier trifft man auf umfassende Erfahrung, die man auch an anderer Stelle im Unternehmen gut verwenden kann.

Bots ersetzen repetitive, eher stupide menschliche Routinetätigkeit und entlasten damit die Controller. Bevor sie das können, müssen die Controller aber tief in die Geschäftsprozesse einsteigen und ins Detail gehend und präzise Prozesse analysieren und gestalten. Im zweiten Schritt kann dann Künstliche Intelligenz den Einsatz von Bots ergänzen, etwa bei der Sicherung der Datenqualität. Von spannender Entscheidungsunterstützung ist zwar beides weit entfernt, aber ein effizientes und stabiles Backoffice schafft die für Entscheidungsunterstützung und Business Partnering notwendigen Freiräume. $\mathrm{Ob}$ und wie diese dann genutzt werden, steht allerdings auf einem anderen Blatt.

Viel Vergnügen bei der Lektüre wünschen Ihnen
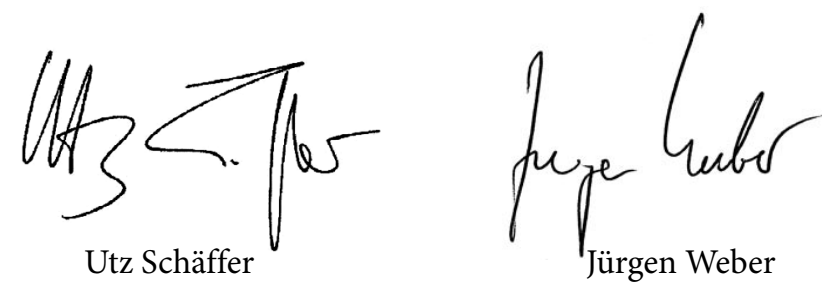